\title{
Investigation of Quantity, Quality and Energy Content of Indigenous Sugarcane Trash in Naoshehro Feroze District, Sindh
}

\author{
Sajjad Hussain Solangi \\ Department of Mechanical Engineering, \\ Quaid-e-Awam University College of \\ Engineering, Science and Technology, \\ Larkano, Pakistan \\ sajjad05me14@yahoo.com
}

\author{
Abdul Qayoom Jakhrani \\ Department of Chemical Engineering, \\ Quaid-e-Awam University of \\ Engineering, Science and Technology, \\ Nawabshah, Pakistan \\ aqunimas@hotmail.com
}

\author{
Kishan Chand Mukwana \\ Department of Energy and Environment \\ Engineering, Quaid-e-Awam University \\ of Engineering, Science and Technology, \\ Nawabshah, Pakistan \\ kcmukwana@quest.edu.pk
}

\author{
Abdul Rehman Jatoi \\ Department of Energy and Environment Engineering, \\ Quaid-e-Awam University of Engineering, Science and \\ Technology, Nawabshah, Pakistan \\ arjatoi@quest.edu.pk
}

\author{
Muhammad Ramzan Luhur \\ Department of Mechanical Engineering, \\ Quaid-e-Awam University of Engineering, Science and \\ Technology, Nawabshah, Pakistan \\ ramzanluhur@yahoo.com
}

\begin{abstract}
Quantity, characteristics, and energy content in sugarcane trash of six different indigenous sugarcane varieties were computed for their possible utilization. Results revealed that the total sugarcane trash weight percentage was $24.0 \%$ of the total sugarcane crop. Among all examined varieties, variety 240 produced the highest and the variety HS12 the lowest percentage of sugarcane trash with $28 \%$ and $18.6 \%$ respectively. Moisture and ash content were found less in brown leaves and more in the tops of sugarcane trash parts. The fixed carbon values in brown leaves, green leaves, and tops of the variety Thatta10 were the highest found, with $18.4 \%, 15.5 \%$, and $17.3 \%$ respectively. Carbon element's percentage in brown leaves of variety HS12 was the highest with $50.0 \%$ and in Thatta10 was the lowest with $43.4 \%$. Highest heating value was found in Thatta10 with $16.0 \mathrm{MJ} / \mathrm{kg}$, which is close to the literature reported values.
\end{abstract}

Keywords-energy content; higher heating value; proximate analysis; ultimate analysis; sugarcane trash

\section{INTRODUCTION}

The major sources of biomass are crop residues, animal manure and municipal solid waste. Some major crop residues are wheat straw, rice husk, rice straw, sugarcane trash, bagasse and cotton sticks [1]. Sugarcane is a suitable agricultural energy crop [2]. Sugarcane crop can be divided into different parts: stem, fresh leaves, and dry leaves. Sugarcane trash is the field residue remaining after harvesting green leaves (fresh leaves), dry leaves (brown leaves) and tops. The brown sugarcane trash almost remains un-utilized and is burnt openly in the fields and the remaining trash (green leaves and tops) is collected to feed farm animals [2]. Sugarcane produces mainly two types of biomasses, namely sugarcane trash and bagasse. Sugarcane trash or cane trash is an excellent biomass resource, as it is being used as a raw material for energy production. The worldwide bioenergy potential of sugarcane trash is around $9475 \mathrm{GWh} /$ year [3].

It is estimated that around 26,280,000 hectares of land are under cultivation in Pakistan [3]. Sugarcane is one of the major crops in Pakistan, being cultivated on 1,029,000 hectares in 2010-2011, which is about $4 \%$ of the total cropped area in the country. It is estimated that about 5,752,800 metric tonnes of sugarcane trash are being generated from a total sugarcane production of $63,920,000$ metric tonnes $[4,5]$. The production of sugarcane trash depends on the plant variety, crop age, type of soil and weather conditions of the area. There are different varieties of the sugarcane in Pakistan. These differ from each other in color, production magnitude and size. The major sugarcane varieties cultivated in Sindh province are Thatta10, 240, 246, 234, HS12 and Sibea. The yield of the sugarcane crop can be estimated by measuring the production of the sugarcane (tonnes) per unit of cultivated area (acre). The sugarcane trash quantity can be evaluated by measuring the sugarcane trash produced per unit tonne of the sugarcane crop. It is reported that the average sugarcane trash (green leaves, brown leaves and tops) per yield (tonne) of sugarcane crop is around $13 \%$ [6] and $15 \%$ [3]. The energy content of the sugarcane trash can be determined either through direct measurement of the heating value of the crop residue through bomb calorimeter or indirectly by proximate and ultimate analysis. In proximate analysis, moisture content, volatile matter, ash content and fixed carbon are determined. In ultimate analysis, the quantitative analysis of various elements present in the matter such as carbon, hydrogen, sulfur, oxygen, and nitrogen is determined. The proximate and ultimate analysis of the sugarcane trash showed that the volatile matter 
was $74 \%$ to $80 \%$, ash $6 \%$ to $10 \%$, and fixed carbon $12 \%$ to $17 \%$. The moisture content in sugarcane trash was about $19.3 \%$ $[7,8]$. The tops of sugarcane contained $1.5 \%$ to $5 \%$ more fixed carbon than the leaves. The heating values of sugarcane trash ranged from 17.7 to $18.9 \mathrm{MJ} / \mathrm{kg}$ [7], and 17 to $21 \mathrm{MJ} / \mathrm{kg}$ [9]. Nitrogen $(\mathrm{N})$, sulfur $(\mathrm{S})$, and chlorine $(\mathrm{Cl})$ in the trash were less than $1 \%$. Authors in [10] and [11] determined the proximate and ultimate analysis of sugarcane trash as shown in Tables I and II respectively. Sugarcane leaves were found as sustainable biomass feedstock for the production of biofuels. Authors in [12] reported that the sugarcane tops, leaves and bagasse can generate $9 \mathrm{TWh}$ electricity in Thailand, which could decrease greenhouse gas emissions by $4.8 \mathrm{Mt}$ of $\mathrm{CO}_{2}$ equivalents per year. Author in [13] reported that about one-third of the energy is available in the tops and leaves of sugarcane crop. At present, sugarcane residues in Pakistan are being burnt outdoors, which not only damages the natural environment but it is also a waste of energy. Sugarcane growers do not have the knowledge of its energy content, and environmental benefits. Besides, there is no proved scientific method for proper quantification and quality analysis of sugarcane trash. The purpose of this study was to determine and quantify the composition and energy content of sugarcane trash in district Naushahro Feroze of Sindh province, Pakistan.

TABLE I. PROXIMATE AND ULTIMATE ANALYSIS RESULTS [10]

\begin{tabular}{|c|c|c|c|}
\hline \multicolumn{2}{|c|}{ Proximate analysis } & \multicolumn{2}{c|}{ Ultimate analysis } \\
\hline Properties & Values & Properties & Values \\
\hline Fixed carbon [wt.\%] & 21.26 & Carbon $(\mathrm{C})$ & 51.21 \\
\hline Volatile matter [wt.\%] & 70.86 & Hydrogen $(\mathrm{H})$ & 5.16 \\
\hline Moisture content [wt.\%] & 4.55 & Nitrogen $(\mathrm{N})$ & 1.93 \\
\hline Ash [wt.\%] & 3.33 & Oxygen $(\mathrm{O})$ & 40.33 \\
\hline Heating Value [MJ/kg] & 18.3 & Sulfur $(\mathrm{S})$ & 1.37 \\
\hline
\end{tabular}

TABLE II. PROXIMATE AND ULTIMATE ANALYSIS RESULTS [11]

\begin{tabular}{|c|c|c|c|c|}
\hline \multicolumn{5}{|c|}{ Proximate Analysis (\% weight) } \\
\hline Parameters & $\begin{array}{c}\text { Dry } \\
\text { leaves }\end{array}$ & $\begin{array}{c}\text { Green } \\
\text { Leaves }\end{array}$ & Tops & Bagasse \\
\hline Moisture Content & 13.5 & 67.7 & 82.3 & 50.2 \\
\hline Ash & 3.9 & 3.7 & 4.3 & 2.2 \\
\hline Fixed Carbon & 11.6 & 15.7 & 16.4 & 18 \\
\hline Volatile Matter & 84.5 & 80.6 & 79.3 & 79.9 \\
\hline \multicolumn{5}{|c|}{ Ultimate Analysis (\%) } \\
\hline Carbon (C) & 46.2 & 45.7 & 43.9 & 44.6 \\
\hline Hydrogen (H) & 6.2 & 6.2 & 6.1 & 5.8 \\
\hline Nitrogen (N) & 0.5 & 1.0 & 0.8 & 0.6 \\
\hline Oxygen (O) & 43.0 & 42.8 & 44.0 & 44.5 \\
\hline Sulfur (S) & 0.1 & 0.1 & 0.1 & 0.1 \\
\hline Chlorine (Cl) & 0.1 & 0.4 & 0.7 & 0.02 \\
\hline
\end{tabular}

\section{MATERIALS AND METHODS}

\section{A. Study Area}

The study was carried out in the geographical area of Naushahro Feroze district, Sindh, Pakistan. The district is located at the center of Sindh province covering an area of $2,945 \mathrm{~km}^{2}$. In this district, about 25 to 30 thousand acres are being used for cultivation of sugarcane, and a huge quantity of sugarcane trash is produced and wasted. The average sugarcane yield per acre is about 20 tonnes with the sugarcane trash of around 4.8 tonnes. Two fields in the district, namely, Dhearan and Moro were selected for collection, quantification, and characterization of sugarcane trash samples. Six varieties of sugarcane crop, namely 240, Sibea, 234, HS12, Thatt10 and 246 were investigated.

\section{B. Quantification of Sugarcane Trash}

The quantification of the sugarcane trash was done by estimating the total cultivated area of the sugarcane crop and by the knowing of the average sugarcane trash (brown leaves, green leaves and tops) quantity produced per tonne and sugarcane crop. The total sugarcane cultivated area in the district was estimated by survey, interviews of farmers, landlords and administrators of different sugar mills, and through satellite pictures. The production of sugarcane trash per tonne of sugarcane crop was determined by taking $40 \mathrm{~kg}$ of sugarcane crop of each variety from the selected fields. The sugarcane trash produced per $40 \mathrm{~kg}$ of the crop was weighted. Green leaves (GL), brown leaves (BL) and tops of each variety were collected and weighted separately.

\section{Characteristic and Energy Content of Sugarcane Trash}

The characteristic and energy content of sugarcane trash was determined by taking three samples of each variety. Proximate and ultimate sample analyses were carried out for the determination of their physical and chemical characteristics, and indirect computation of energy content. The energy content or heating value of the samples was also directly determined using bomb calorimeter. In proximate analysis, moisture, volatile matter, ash, and fixed carbon content were determined. The moisture content (MC) of the samples was computed by the percentage of loss in weight. The equipment used was a drying oven, china crucible of $32 \mathrm{cc}$ volume, electronic micro balance and desiccators following the ASTM-E871. The MC of the samples was determined by (1) [16]:

$$
M C[\%]=\left(\frac{W_{i}-W_{f i}}{W_{i}-W_{c}}\right) \times 100
$$

where $W_{i}$ is the initial sample weight, $W_{f i}$ is the final sample weight and $W_{c}$ is the crucible weight. The volatile matter (VM) was found by percentage in weight loss by ASTM-E872. The equipment used was chromium-nickel crucible with lid and an electrically operated electric furnace. The VM content of the samples was determined by (2) [16]:

$$
V M[\%]=100 \times\left(\frac{W_{i}-W_{f i}}{W_{i}-W_{c}}\right) \times 100
$$

Similarly, the ash content (AC) of the samples was calculated by the mass percentage of the remains after process of dry oxidation at $575{ }^{\circ} \mathrm{C}$ for a time period of 3 hours by adopting ASTM-E1755. The equipment used was a crucible, electric muffle furnace, drying oven and desiccator. The AC of the samples was determined by (3):

$$
\text { Ash [\%] }=\left(\frac{m_{\text {ash }}-m_{\text {cont }}}{m_{\text {od }}-m_{\text {cont }}}\right) \times 100
$$

where $m_{a s h}$ is the final mass of the ash, $m_{\text {cont }}$ is the tare of the container, and $m_{o d}$ is the initial mass of $105^{\circ} \mathrm{C}$ dried sample and container. The fixed carbon (FC) was calculated from the 
resultant of the summation of the percentage of $\mathrm{MC}, \mathrm{VM}$ and AC subtracted from 100 as in (4):

$$
F C[\%]=100-M C[\%]-V M[\%]-A s h[\%]
$$

The ultimate (elemental) analysis of the samples was carried out by adopting the procedures given by the Association of Official Analytical Chemists (AOAC), (AOAC2005), and International Organization for Standardization (ISO-17025). In this analysis carbon, hydrogen, nitrogen, sulfur and oxygen concentrations of the samples were determined. The total carbon content of sugarcane trash samples was estimated by dividing the organic matter with the factor 1.82 [17]. The amount of the hydrogen was measured using thermo scientific flash method (thermo scientific Flash EA series USA). Total nitrogen content was measured using Kjeldahl apparatus BUCHI K-314, with $0.1 \mathrm{M} \mathrm{NaOH}$ as standardized titrant and $0.50 \%$ methyl red solution was employed as an indicator. The sulfur content was computed as per ASTM-2007 by precipitating sulfur in the form of $\mathrm{BaSO}_{4}$ using $40 \% \mathrm{BaCl}_{2}$ solution. Oxygen content of the samples was calculated with the use of the difference method by using (5):

$$
O[\%]=100-C[\%]-H[\%]-S[\%]-N[\%]-A s h[\%](5)
$$

Energy content, i.e. the higher heating value (HHV) of sugarcane trash samples was determined using adiabatic bomb calorimeter by adopting ASTM-E-711. The calibration of the calorimeter was done by the burning of benzoic acid. After that, the burned sample was weighted. Finally, the HHV was determined by the difference of the temperature before and after combustion taking place. Moreover, the quantification of sugarcane samples and their characteristics were compared with the results of other studies. The comparison was done in order to know the quantity and quality of sugarcane with respect to other areas of the world, whether the results obtained provide similar trends or variations from other researchers.

\section{RESULTS AND DISCUSSION}

The results include quantification, proximate and ultimate analysis, and energy content of different sugarcane trash varieties.

\section{A. Quantification of the Sugarcane Trash}

The total average sugarcane trash was found about $24 \%$ of the sugarcane crop. Average GL, BL, and tops produced per $40 \mathrm{~kg}$ of sugarcane crop were $8 \%, 11 \%$ and $5 \%$ respectively. It is observed that the variety 240 gave $11.19 \mathrm{~kg} / 40 \mathrm{~kg}(28.0 \%)$, which is the largest quantity and the variety HS12 gave $7.42 \mathrm{~kg} / 40 \mathrm{~kg}(18.6 \%)$, which is the least quantity among all examined sugarcane crop varieties (Figure 1). It is shown that the variety 240 showed maximum BL value with $5.16 \mathrm{~kg} / 40 \mathrm{~kg}$, and Sibea BL had the minimum value with $4.08 \mathrm{~kg} / 40 \mathrm{~kg}$. Similarly, the maximum GL quantity was produced from the variety 234 and was $4.0 \mathrm{~kg} / 40 \mathrm{~kg}$ and the minimum was from HS12 with a value of $2.0 \mathrm{~kg} / 40 \mathrm{~kg}$. Likewise, the top produced from the variety 240 was $3.0 \mathrm{~kg} / 40 \mathrm{~kg}$ which was the greater, and HS12 produced $1.2 \mathrm{~kg} / 40 \mathrm{~kg}$, which was the lowest among all examined varieties. The average values of BL, GL and tops produced from all varieties were $4.5 \mathrm{~kg}, 3.3 \mathrm{~kg}$ and $2.2 \mathrm{~kg}$ respectively.

\section{B. Characterization of the Sugarcane Trash}

The characterization of the sugarcane trash consists of proximate and ultimate analysis.

\section{1) Proximate Analysis}

The results of proximate analysis of the sugarcane trash samples are presented in Figure 2, with moisture content (MC), volatile matter (VM), ash and fixed carbon (FC) measured for each part of each variety. MC in the brown leaves of all examined varieties was less, and tops was more among the different parts of sugarcane trash. The average moisture content in $\mathrm{BL}, \mathrm{GL}$ and tops was $5.0 \%, 6.6 \%$ and $37.0 \%$ respectively. The least MC was found in BL of Sibea with $2.3 \%$, the GL of 246 with $4.7 \%$, and the tops of 234 with $23.6 \%$ therefore, these parts of sugarcane trash were found more practicable. As far as the VM was concerned, it was found more in the BL and less in the tops.

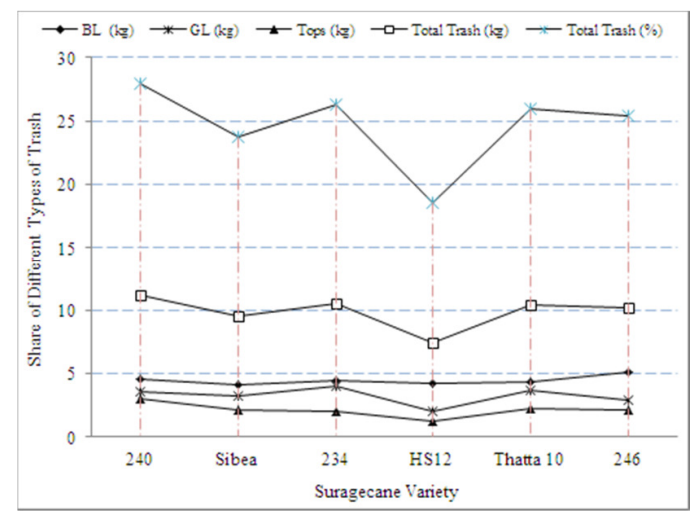

Fig. 1. Weight of sugarcane trash per $40 \mathrm{~kg}$ of sugarcane crop.

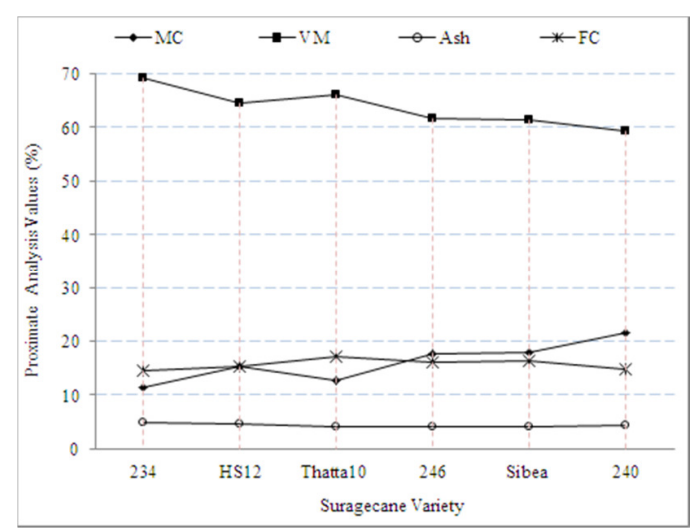

Fig. 2. Average proximate analysis results of sugarcane trash.

The average VM of all the varieties in BL, GL and tops is $75.1 \%, 74.4 \%$ and $41.5 \%$ respectively. In general, the VM in the tops was less and in the BL more among the other parts in all varieties. The average ash content (AC) was found more in the tops, and less in the BL as compared to different parts of sugarcane trash. The average $\mathrm{AC}$ in $\mathrm{BL}, \mathrm{GL}$ and tops was $3.8 \%, 4.3 \%$ and $4.9 \%$ respectively. The average $\mathrm{FC}$ was found greater in the $\mathrm{BL}$, and less in the GL as compared to different parts of sugarcane trash. The average FC in BL, GL and tops 
was $16.7 \%, 14.5 \%$ and $15.9 \%$ respectively among all varieties. FC content was found greater in Thatta 10 . The FC content in BL, GL and tops of Thatta 10 were $18.4 \%, 15.5 \%$ and $17.3 \%$ respectively. The FC content was found less in the GL and more in BL than the other parts of sugarcane trash.

\section{2) Ultimate Analysis}

The results of ultimate analysis are given in Figures 3 to 5 . Three samples of each part of sugarcane trash of all varieties were examined. It was found that the percentage of carbon is greater than other elemental percentages in the samples with oxygen being the second major element. The carbon percentage of all varieties and samples lied between $40 \%$ and $50 \%$. The percentage of hydrogen ranged from $3.5 \%$ to $6 \%$, nitrogen ranged from $0.25 \%$ to $1 \%$, oxygen ranged from $34.5 \%$ to $42.5 \%$ and sulfur ranged from $0.13 \%$ to $0.21 \%$. The average values of carbon in BL, GL, and tops were found $46.6 \%$, $44.3 \%$ and $41.8 \%$ respectively. The respective hydrogen percentage was $5.0 \%, 4.8 \%$ and $4.4 \%$. Likewise, the nitrogen percentage was $0.4 \%, 0.8 \%$ and $0.62 \%$ respectively. The oxygen percentage was $39.7 \%, 37.5 \%$ and $39.0 \%$ and the sulfur percentage was $0.2 \%, 0.2 \%$ and $0.2 \%$.

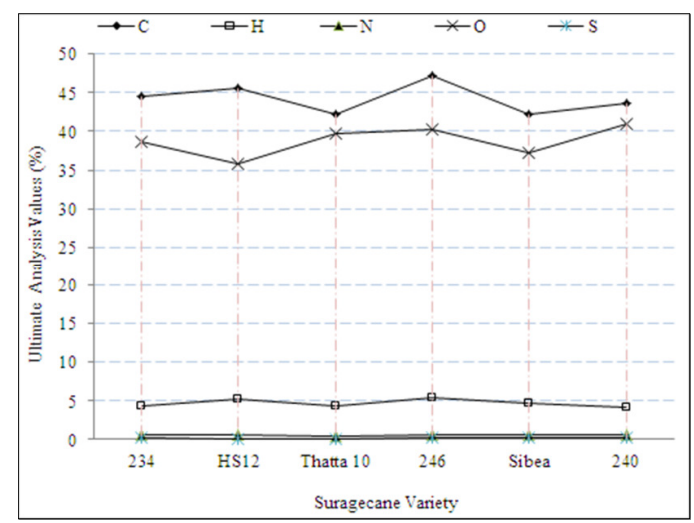

Fig. 3. Ultimate analysis results of different varieties of sugarcane trash

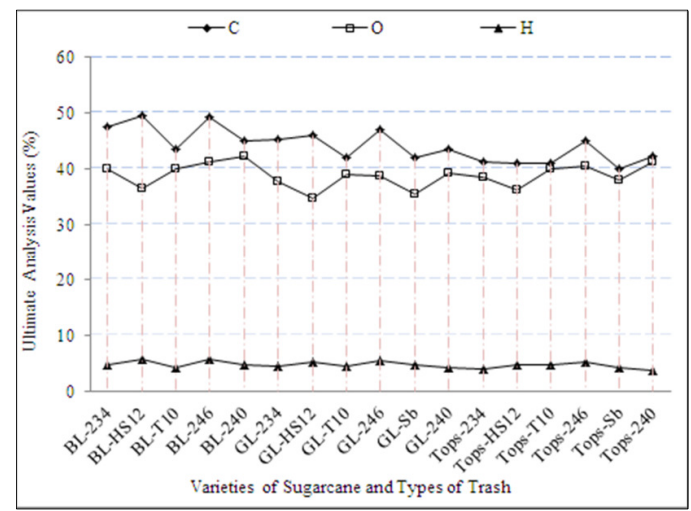

Fig. 4. Ultimate analysis results of different components of sugarcane trash

\section{3) Higher Heating Value}

Energy content i.e. the HHV of the sugarcane trash was determined with the help of a bomb calorimeter. Eighteen samples of all parts of sugarcane trash, namely BL, GL and tops of all six varieties were examined as shown in Figure 6. The recorded results showed that the energy content of the sampled BL lied between 14.0 and $17.7 \mathrm{MJ} / \mathrm{kg}$. The heating value of the sampled GL lied between 10.0 and $13.7 \mathrm{MJ} / \mathrm{kg}$. The heating value in tops was found between 11.0 and $15.0 \mathrm{MJ} / \mathrm{kg}$.

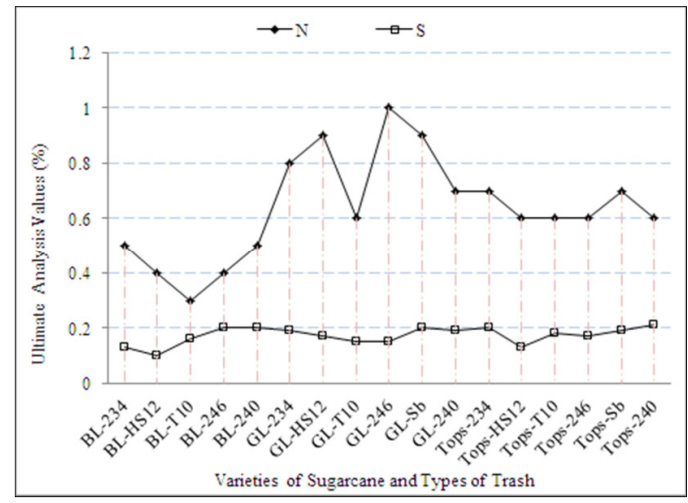

Fig. 5. Nitrogen and sulphur content of different components of sugarcane trash

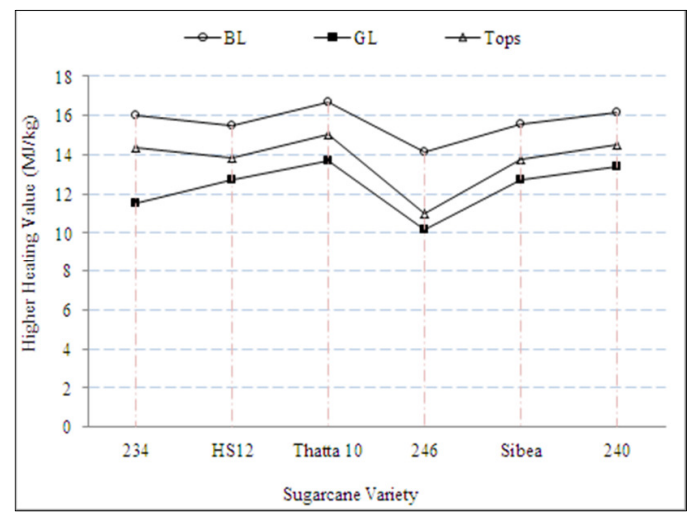

Fig. 6. Energy content of different varieties of sugarcane trash

It is observed that BL had the highest average HHV and GL the lowest among the other parts of sugarcane trash. The average heating values were: $16.0 \mathrm{MJ} / \mathrm{kg}$ for $\mathrm{BL}, 12.5 \mathrm{MJ} / \mathrm{kg}$ for $\mathrm{GL}$ and $14 \mathrm{MJ} / \mathrm{kg}$ for tops.

\section{OBTAINED RESULTS-REPORTED VALUES COMPARISON}

The results obtained during quantification, proximate and ultimate analysis and HHV were compared with the work of other researchers in the same field. The total sugarcane trash quantity in weight percentage reported in [18] was $25.0 \%$ and $23.0 \%$ in [13] and the obtained value was $24.0 \%$. The BL percentages reported in [11] and [13] were $14.0 \%$ and $12.3 \%$ respectively, whereas, the measured value was slightly less with $11.0 \%$. Regarding the results of proximate analysis, it was found that the $\mathrm{MC}$ in $\mathrm{BL}, \mathrm{GL}$ and tops of sugarcane trash determined in [11] were $13.5 \%, 67.7 \%$ and $82.3 \%$ and the obtained values were $5.0 \%, 6.6 \%$ and $37.0 \%$. The VM content $\mathrm{VM}$ in BL, GL, and tops of sugarcane trash determined in [11] were $84.5 \%, 67.7 \%$ and $79.3 \%$ and the obtained values were $75.1 \%, 74.4 \%$ and $41.5 \%$ respectively. The $\mathrm{AC}$ in $\mathrm{BL}, \mathrm{GL}$ and 
tops of sugarcane trash determined in [11] were 3.9\%, 3.7\% and $4.3 \%$, and the obtained values were $3.8 \%, 4.3$ and $4.9 \%$. The FC content in BL, GL and tops determined in [11] were $11.6 \%, 15.7$ and $16.4 \%$ and the obtained values were $16.7 \%$, $14.5 \%$ and $15.9 \%$. Regarding the ultimate analysis parameters, the carbon percentage reported in [11] and [10] was $45.3 \%$ and $51.2 \%$ respectively and the measured values were $44.2 \%$. The hydrogen content given in [11] was $6.2 \%$ and in [10] 5.2\% and the measured value was $4.7 \%$. The nitrogen given in [11] was $0.8 \%$ and in [10] $1.9 \%$, and the measured one was $0.6 \%$. The oxygen level reported in [11] was $43.3 \%$ and in [10] $40.3 \%$, while the measured value was $38.7 \%$. The sulphur percentage reported in [11] was $0.1 \%$, in [10] $1.4 \%$ and the measured value was $0.2 \%$. The energy content (i.e. HHV) of sugarcane trash reported in [11] was $17.1 \mathrm{MJ} / \mathrm{kg}$ and in [10] $18.3 \mathrm{MJ} / \mathrm{kg}$, while the measured value was $16.0 \mathrm{MJ} / \mathrm{kg}$. It is found that all results are comparable with the reported values of other researchers.

\section{CONCLUSIONS}

The total sugarcane trash weight percentage reported by two different researchers was $25.0 \%, 23.0 \%$, and the measured value was $24.0 \%$. The variety 240 produced the highest, and the variety HS12 the lowest percentage of sugarcane trash with $28 \%$ and $18.6 \%$ respectively among all examined varieties. Moisture and $\mathrm{AC}$ in $\mathrm{BL}$ was less and the tops gave more among sugarcane trash components and examined varieties. The FC values in BL, GL and tops of Thatta10 were found the greatest with $18.4 \%, 15.5 \%$ and $17.3 \%$ respectively. On the basis of ultimate analysis, the most carbon percentage was found in the BL of HS12 and the least in Thatta10. The HHV in the BL of sugarcane trash samples reported in [11], [10] and [19] were $17.1 \mathrm{MJ} / \mathrm{kg}, 18.3 \mathrm{MJ} / \mathrm{kg}$ and $17.4 \mathrm{MJ} / \mathrm{kg}$ respectively and the measured value was $16.0 \mathrm{MJ} / \mathrm{kg}$. The obtained value of energy content in the examined samples and the reported values were found comparable with $\pm 6 \%$ diversity. It is suggested that the quantification of different components of sugarcane trash may be carried out separately using different varieties and areas with higher, moderate and lower yield fields. Water and soil analysis may be carried out in order to see the reason behind sugarcane crop yield variation. In addition, sugarcane trash samples may be tested for making charcoal briquettes and for cogeneration systems with biomass gasification gas turbine integrated with sugar mills.

\section{REFERENCES}

[1] N. Aziz, "Biomass energy potential in Pakistan", available at: https://www.bioenergyconsult.com/biomass-pakistan, 2018

[2] T. Suramaythangkoor, Z. Li, "Energy policy tools for agricultural residues utilization for heat and power generation: A case study of sugarcane trash in Thailand", Renewable and Sustainable Energy Reviews, Vol. 16, No. 6, pp. 4343-4351, 2012

[3] S. Zafar, "Biomass resources from sugar industry", available at: https://www.bioenergyconsult.com/biomass-resources-from-sugarindustry, 2018

[4] B. Patel, B, Gami, "Biomass characterization and its use as solid fuel for combustion", Iranica Journal of Energy \& Environment, Vol. 3, No. 2, pp. $123-128,2012$

[5] D. Szczerbowski, A.P. Pitarelo, A. Zandona Filho, L. P. Ramos, "Sugarcane biomass for biorefineries: comparative composition of carbohydrate and non-carbohydrate components of bagasse and straw", Carbohydrate Polymers, Vol. 114, pp. 95-101, 2014

[6] F. J. Tian, J. L. Yu, L. J. Mckenzie, J. I. Hayashi, T. Chiba, C. Z. Li, "Formation of NOx precursors during the pyrolysis of coal and biomass. Part VII. Pyrolysis and gasification of cane trash with steam", Fuel, Vol. 84, No. 4, pp. 371-376, 2005

[7] S. Q. Turn, V. Keffer, M. Staackmann, Analysis of Hawaii Biomass Energy Resources for Distributed Energy Applications, Honolulu: Hawaii Natural Energy Institute, University of Hawaii, 2002

[8] M. R. L. Leal, M. V. Galdos, F. V. Scarpare, J. E. Seabra, A. Walter, C. O. Oliveira, "Sugarcane straw availability, quality, recovery and energy use: A literature review", Biomass and Bioenergy, Vol. 53, pp. 11-19, 2013

[9] K. Deepchand, "Characteristics, Present use and potential of sugar cane tops and leaves", Agricultural Wastes, Vol. 15, No. 2, pp. 139-48, 1986

[10] W. Treedet, R. Suntivarakorn, "Sugar cane trash pyrolysis for bio-oil production in a fluidized bed reactor", World Renewable Energy Congress, Linkoping, Sweden, May 8-13, 2011

[11] S. J. Hassuani, M. R. L. V. Leal, I. Macedo, Biomass Power Generation, Sugar Cane Bagasse and Trash, Programa das Nacoes Unidas Para o Desenvolvimento and Centro De Technologi a Canavieriva, Peracicaba, Brazil, 2005

[12] S. Jenjariyakosoln, S. H. Gheewala, B. Sajjakulnukit, S. Garivait, "Energy and GHG emission reduction potential of power generation from sugarcane residues in Thailand", Energy for Sustainable Development, Vol. 23, pp. 32-45, 2014

[13] L. Smithers, "Review of sugarcane trash recovery systems for energy cogeneration in South Africa", Renewable and Sustainable Energy Reviews, Vol. 32, pp. 915-925, 2014

[14] H. Jin, E. D. Larson, F. E. Celik, "Performance and cost analysis of future, commercially mature gasification-based electric power generation from switchgrass", Biofuels, Bioproducts and Biorefining, Vol. 3, No. 2, pp. 142-173, 2009

[15] V. Mangut, E. Sabio, J. Ganan, J. F. Gonzalez, A. Ramiro, C. M. Gonzalez, A. Al-Kassir, "Thermogravimetric study of the pyrolysis of biomass residues from tomato processing industry", Fuel Processing Technology, Vol. 87, No. 2, pp. 109-115, 2006

[16] N. Cellatoglu, M. Ilkan, "Solar torrefaction of solid olive mill residue", Bio Resources, Vol. 11, No. 4, pp. 10087-10098, 2016

[17] G. Selvaraju, N. K. A. Bakar, "Production of a new industrially viable green-activated carbon from Artocarpus integer fruit processing waste and evaluation of its chemical, morphological and adsorption properties”, Journal Of Cleaner Production, Vol. 141, pp. 989-999, 2017

[18] B. Nachiappan, Z. Fu, M. T. Holtzapple, "Ammonium carboxylate production from sugarcane trash using long-term air-lime pretreatment followed by mixed-culture fermentation", Bioresource Technology, Vol. 102, No. 5, pp. 4210-4217, 2011

[19] J. Parikh, S. A. Channiwala, G. K. Ghosal, "A correlation for calculating HHV from proximate analysis of solid fuels", Fuel, Vol. 84, No. 5, pp. 487-494, 2005 